\title{
Relações entre desenvolvimento profissional e coordenação de Projetos PIBID: um estudo bibliográfico
}

Professional development and PIBID Supervisors relationship: a bibliographic survey

\author{
Caian Cremasco Receputi \\ Daisy de Brito Rezende
}

Resumo: Este artigo tem por objetivo apresentar os resultados de uma revisão bibliográfica sobre a relação entre o desenvolvimento profissional de professores do Ensino Superior e a coordenação de projetos PIBID. Para tanto, realizou-se um estudo bibliográfico narrativo, preliminar e não sistemático sobre os temas mencionados, abrangendo documentos legais, artigos, Teses e Dissertações. Os documentos selecionados foram organizados, codificados e analisados segundo os pressupostos da Análise de Conteúdo. Realizou-se uma discussão em três frentes analíticas: conceitual, contextual e investigativa. Na perspectiva conceitual, procura-se discutir sobre o desenvolvimento profissional de professores universitários, suas características e especificidades; na contextual, analisam-se os documentos legais sobre a implementação do PIBID e as atribuições do Coordenador de Área; e, na investigativa, apresentam-se os resultados de pesquisas sobre a potencialidade do PIBID para o desenvolvimento profissional dos Coordenadores de Área. Os resultados do estudo bibliográfico mostram que: i) há necessidade da implementação de programas que contribuam para o desenvolvimento da profissionalidade docente dos professores do Ensino Superior; ii) o PIBID vem passando por diversas alterações ao longo dos anos: inicialmente, essas alterações foram profícuas, porém, nos últimos anos, tem-se caracterizado por prejudicarem a política de formação de professores; iii) as atribuições do Coordenador de Área mostram sua importância no planejamento das atividades do PIBID, sendo que diversas ações possibilitam seu desenvolvimento profissional; e iv) coordenar projetos PIBID contribui para o desenvolvimento profissional do docente, especialmente, pela aproximação da realidade escolar da Educação Básica e pelo trabalho colaborativo entre os atores do PIBID. Conclui-se que o PIBID tem contribuído para o desenvolvimento profissional dos Coordenadores de Área, o que pode se refletir na formação dos licenciandos, sejam eles participantes PIBID ou não.

Palavras-chave: Desenvolvimento Profissional; Coordenador de Área; PIBID; Estudo Bibliográfico.

Abstract: This article aims to present the results of a literature review on the relationship between the professional development of higher education teachers and the coordination of PIBID projects. To this end, a narrative, preliminary and nonsystematic bibliographic study was carried out on the topics mentioned, covering legal documents, articles, Theses and Dissertations. The selected documents were organized, codified and analyzed according to the assumptions of the Content Analysis. A discussion was held on three analytical fronts: conceptual, contextual and investigative. From the conceptual perspective, the aim is to discuss the characteristics and specificities of the professional development of university teachers; in the contextual, the legal documents on the implementation of the PIBID and the Area Coordinator's duties are analyzed; and in the investigative perspective, the results of researches on the potential of the PIBID in the professional development of Area 
Coordinators are presented. The results of the bibliographic study show that: $i)$ there is a need for the implementation of programmes that contribute to the development of the teaching skills of Higher Education teachers; ii) PIBID has undergone several changes over the years: initially, these changes have been fruitful, but in recent years they have been detrimental to teacher training policy; iii) the responsibilities of the Area Coordinators show their importance in the planning of PIBID's activities, involving various actions that enable their professional development; and iv) coordinating PIBID projects contribute to the professional development of Higher Education teachers, especially by bringing the school reality of Basic Education closer together and through collaborative work among PIBID's actors. The conclusion is that PIBID has contributed to the professional development of Area Coordinators, which may be reflected in the initial teacher training of undergraduates, even if they did not participate in PIBID program.

Keywords: Professional Development; Project Supervisor; PIBID; Bibliographic Survey.

\section{Introdução}

A formação docente é um tema de pesquisa amplamente investigado no contexto nacional (SILVA; QUEIROZ, 2017; ANDRÉ, 2009). Enquanto André (2009) realizou um estudo bibliográfico sobre formação de professores abrangendo Teses e Dissertações na área de Educação entre os anos de 1999 e 2003, Silva e Queiroz (2017) mapearam as Teses e Dissertações sobre formação de professores de Química defendidas em Programas de PósGraduação em Química, Educação e Ensino de Ciências e Matemática, entre 2001 e 2010. Um dos diversos resultados dessas pesquisas mostra que a maior parte delas investigam a formação inicial de professores, uma parte menor investiga a formação continuada do professor da Educação Básica, enquanto o desenvolvimento profissional do professor universitário é o tema menos pesquisado dentre os estudos identificados.

Porém, as universidades públicas têm passado por diversas transformações nas últimas décadas. Uma delas refere-se ao processo de expansão do número de vagas, proveniente de demandas da própria sociedade (CHAUÍ, 2003). A expansão do número de vagas na graduação acarreta a massificação do ensino, o que modifica a atuação docente, especialmente a função de ensino, visto que a função de pesquisa tem sido a principal fonte de prestígio na atividade acadêmica (CHAMLIAN, 2003).

A formação do professor universitário tem, paulatinamente, ganhado espaço nas discussões universitárias e nas pesquisas científicas sobre 
formação docente (CHAMLIAN, 2003). Reflexo disso é o número expressivo de Instituições Federais de Ensino Superior que declaram desenvolver alguma política institucional de desenvolvimento profissional para os docentes (OLIVEIRA JUNIOR; PRATA-LINHARES; KARWOSKI, 2018).

Considerando o contexto descrito acima, a pergunta que norteia $\mathrm{O}$ desenvolvimento desta pesquisa é se o Programa Institucional de Bolsa de Iniciação à Docência (PIBID), para além de seus objetivos principais (veja no tópico a construção do PIBID a partir dos documentos legais), também atuaria no desenvolvimento profissional dos professores universitários, Coordenadores de Área. Esta pergunta se justifica ao se analisar os relatórios da Diretoria de Formação de Professores da Educação Básica (DEB), em que é possível perceber que os próprios Coordenadores de Área compreendem que o PIBID tem contribuído para seu desenvolvimento profissional (CAPES-DEB, 2012; 2013; 2014). A identificação e compreensão destas possíveis especificidades podem contribuir para a reflexão acerca da formação e atuação dos Coordenadores de Área tanto em subprojetos PIBID como nos cursos de Licenciatura aos quais estão vinculados. Este aspecto é importante pela sua possível influência nos currículos praticados nas Licenciaturas, que configuram o processo formativo inicial do futuro professor, que irá se manifestar durante sua prática em sala de aula da Educação Básica.

\section{Percurso Metodológico}

Este artigo propõe-se a discutir a relação entre coordenação de projetos PIBID e o desenvolvimento profissional de professores do Ensino Superior, considerando três frentes analíticas, de natureza conceitual, contextual e investigativa (como proposto por CRUZ, 2017). A primeira delas, de natureza conceitual, refere-se à discussão sobre o desenvolvimento profissional de professores do Ensino Superior, suas características e especificidades. A segunda frente analítica, de natureza contextual, ocupa-se de apresentar sinteticamente as discussões sobre a constituição do PIBID e as atribuições do Coordenador de Área. A terceira frente analítica, de natureza investigativa, tem 
como ênfase os resultados de pesquisas sobre a potencialidade do PIBID no desenvolvimento profissional docente dos Coordenadores de Área.

Para a obtenção das informações, realizou-se um estudo bibliográfico narrativo, preliminar e não sistemático (CORDEIRO et al., 2007). Em relação à frente analítica contextual, optou-se por realizar uma análise documental sobre a gênese, desenvolvimento e estrutura do PIBID, norteada pela definição das atribuições do Coordenador de Área, suas ações, interações e espaços de atuação. Para tanto, analisaram-se os documentos legais e oficiais sobre o PIBID, por meio de Portarias Normativas e editais (Apêndice A).

Para as frentes analíticas conceitual e investigativa, buscou-se realizar um mapeamento na literatura que possibilitasse a discussão das temáticas mencionadas, abrangendo artigos, Teses e Dissertações (Apêndices B e C, respectivamente). Enquanto, na frente analítica, buscou-se discutir as características do desenvolvimento profissional dos professores universitários, na frente investigativa apresentam-se os resultados empíricos de estudos sobre a potencialidade do PIBID para o desenvolvimento da profissionalidade docente dos Coordenadores de Área. Os documentos selecionados foram organizados, codificados e analisados segundo os pressupostos da Análise de Conteúdo, inspirada em Bardin (2011). Para tanto, realizou-se a leitura dos documentos na íntegra, passando para o processo de interpretação a partir dos objetivos traçados e a escrita de um metatexto apresentando as inferências dos pesquisadores.

\section{Resultados e Discussão: Formação de Professores do Ensino Superior}

Nesta seção, abordam-se, sucintamente, aspectos do desenvolvimento profissional dos professores do Ensino Superior e suas especificidades em relação à sua formação docente inicial.

A atuação do professor no nível superior de ensino difere em vários aspectos daquela dos professores da escola básica. Nas Instituições de Ensino Superior (IES) que desenvolvem ensino e pesquisa, o profissional em geral é contratado em regime de dedicação exclusiva, principalmente no campo das ciências básicas. Estas especificidades têm contribuído para que a atuação 
docente e, portanto, a formação pedagógica do professor de ensino superior seja relegada a segundo plano. Alguns fatores podem explicar essa problemática:

- historicamente, as atividades de pesquisa são mais valorizadas do que as atividades de ensino (ZANCHET; FELDKERCHER, 2016; JUNGES; BEHRENS, 2013; QUADROS et al., 2012);

- os critérios de avaliação da qualidade docente priorizam a produção de artigos acadêmicos (ZANON; OLIVEIRA; QUEIROZ, 2009);

- ações que estimulem a formação didático-pedagógica dos docentes ainda são incipientes (OLIVEIRA JUNIOR; PRATALINHARES; KARWOSKI, 2018).

Estas especificidades têm contribuído para que os docentes tenham diversas dificuldades no desenvolvimento das atividades referentes ao ensino, por exemplo, insegurança, por não conhecerem estratégias apropriadas para nortear o processo de ensino e aprendizado, gestão da sala de aula e o relacionamento interpessoal com os discentes (FREIRE; FERNANDEZ, 2015).

Isso porque, durante a formação na pós-graduação, docentes e discentes priorizam as atividades de pesquisa em detrimento das atividades de ensino e extensão, por entenderem que a produção de artigos possibilita maiores chances de ingresso e de ascensão na carreira acadêmica (HERMANOWICZ, 2015).

Outro ponto importante a se destacar é a ausência quase total de trocas de experiências pedagógicas entre docentes deste nível de ensino (ZANCHET; FELDKERCHER, 2016). A partilha sobre situações conflitantes ou bemsucedidas possibilitaria fazê-los refletir sobre quais atitudes pedagógicas favorecem o aprendizado dos alunos de graduação, contribuindo para sua formação como futuros docentes do Ensino Superior, como preconiza a legislação brasileira para a capacitação destes profissionais para o magistério 
neste nível de ensino, que se daria no espaço da pós-graduação acadêmica strictu sensu1 (CAPES, 2002).

Entretanto, durante a formação pós-graduada pouco se pensa nas atividades de ensino e no processo de formação necessário para se desenvolverem estas atividades (QUADROS et al., 2012). Mesmo nos casos em que se pergunta explicitamente aos pós-graduandos sobre o que o docente deve saber e saber fazer em sua futura atividade didática, os pós-graduandos enfatizam o domínio do conteúdo especifico da área em detrimento do domínio das estratégias de ensino e da gestão da sala de aula, entre outros saberes e habilidades (ZANON; OLIVEIRA; QUEIROZ, 2009).

Porém, o exercício da docência exige, além dos conhecimentos dos conteúdos específicos da área, conhecimentos didático-pedagógicos e os conhecimentos provenientes da atividade científica (JUNGES; BEHRENS, 2013). Outros autores advogam que os docentes devem saber conciliar esses três conhecimentos (MALDANER; ZANON; AUTH, 2006), embora se tenha percebido a existência desta dicotomia mesmo entre os conhecimentos desenvolvidos pelos pesquisadores em Educação e suas práticas referentes ao processo de ensino e aprendizado.

Para os docentes vinculados a cursos de bacharelado, esta lógica ganha outras dimensões, pois além das atividades acadêmicas estarem voltadas para a sua especialidade, como a escrita e leitura de artigos, participação em bancas, eventos e congressos, eles não desenvolvem conhecimentos pedagógicos, por meio da pesquisa, ou seja, acabam por reproduzir as experiências vivenciadas ao longo de seu processo formativo (JUNGES; BEHRENS, 2013).

Para ambos os casos, há necessidade do desenvolvimento da profissionalidade docente. Para os docentes de cursos de bacharelado, há necessidade de se implementarem ações e programas que contribuam para a

\footnotetext{
${ }^{1}$ Por exemplo, o artigo 17 da Portaria no 52 de 26 de setembro de 2002 define o estágio de docência como parte integrante da formação do pós-graduando, objetivando a preparação para a docência e a qualificação do ensino de graduação, sendo obrigatório para todos os bolsistas do Programa de Demanda Social (CAPES, 2002).
} 
desconstrução de alguns conceitos sobre a docência e a aquisição de novos saberes educacionais (JUNGES; BEHRENS, 2013).

Uma proposta de superação desta dicotomia é por meio de cursos de extensão universitária que possibilitem realizar a integração entre ensino, pesquisa e extensão, por se relacionarem à área de pesquisa específica do pós-graduando em uma atividade de divulgação do conhecimento científico (ARROIO et al. 2008). Assim, o pós-graduando tem a possibilidade de participar em todas as etapas do processo pedagógico, desde a preparação e realização até a avaliação da atividade desenvolvida.

Já para os docentes de cursos de licenciatura ou que pesquisam temáticas relacionadas à Educação, é importante implementar ações e programas que contribuam para que estes docentes desenvolvam novos níveis de consciência sobre o campo educacional, incentivando sua relação com os professores da rede da Educação Básica de ensino e com os alunos do curso de licenciatura (MALDANER, ZANON; AUTH, 2006).

Nos últimos anos, as Instituições Federais de Ensino Superior têm-se voltado para essas questões, já que mais da metade delas vêm desenvolvendo ações de formação para professores do Ensino Superior (OLIVEIRA JUNIOR; PRATA-LINHARES; KARWOSKI, 2018). Porém, esses pesquisadores também identificaram três características comuns a essas políticas: i) são recentes, em grande parte das instituições datam da última década; ii) tendem a se constituir em ações pontuais de formação, envolvendo reflexões sobre a melhoria da prática pedagógica, o desenvolvimento profissional ou atualização, pelo desenvolvimento de conhecimentos específicos; e iii) infelizmente, há uma crescente tendência de implementarem-se ações que redundam em mais uma forma de regulação profissional, ao invés de promoverem a profissionalização docente.

Em síntese, a análise destes estudos possibilita inferir que há necessidade de se implementarem programas de desenvolvimento profissional para os professores do Ensino Superior em sua formação inicial e continuada. Estes programas devem contemplar as especificidades da atuação desses docentes e devem buscar, por meio da discussão e reflexão, sensibilizá-los 
quanto ao processo de ensino e aprendizado, visando a superação dos estigmas atribuídos à docência. Seria interessante a oferta planejamento de atividades diversificadas, abrangendo diferentes formatos, como cursos, palestras e eventos, buscando não os tornar apenas mais uma forma de regulação profissional.

Nesse sentido, se discutirá, no próximo tópico, a construção do PIBID, as principais modificações deste Programa ao longo de sua vigência e as atribuições dos Coordenadores de Área.

\section{A construção do PIBID a partir dos documentos legais: atribuições do Coordenador de Área}

Em 2007, em uma ação do Ministério da Educação, por intermédio da CAPES e do Fundo Nacional de Desenvolvimento da Educação (FNDE), implementa-se o Programa Institucional de Bolsas de Iniciação à Docência (PIBID) por meio da Portaria Normativa ํo 38, de 12 de dezembro de 2007 (MEC-CAPES-FNDE, 2007). Esta Portaria esclarece, dentre outras coisas, que a implementação do PIBID visa incentivar a formação de professores para a Educação Básica e valorizar o magistério, promovendo a melhoria da qualidade da Educação Básica. Esta Portaria restringiu-se aos cursos de formação de professores das Instituições Federais de Educação Superior. Voltou-se, prioritariamente, aos cursos de formação inicial de professores de Química, Física, Biologia e Matemática para atuarem no Ensino Médio, em consequência da carência de profissionais qualificados para ministrarem essas disciplinas, em muitas regiões do País.

A implementação do PIBID foi sistematizada através de convênios entre as Instituições Federais de Educação Superior e a CAPES. Esses convênios concediam bolsas de Iniciação à Docência (a alunos dos cursos de Licenciatura), para o professor supervisor (professor do Ensino Básico) e para o professor coordenador (professor do Ensino Superior). Os alunos da Licenciatura recebem essas bolsas para exercer atividades pedagógicas nas escolas públicas de Educação Básica; a função do Coordenador de Área é a de orientar os alunos nas atividades desenvolvidas na universidade em sintonia 
com os professores da Escola Básica que orientam a atuação dos licenciandos nas escolas.

Porém, não ficam explícitas as atribuições dos bolsistas. No caso do professor Coordenador, há mais requisitos do que atribuições, como pode ser observado no trecho abaixo. O professor Coordenador deverá,

I - pertencer ao quadro efetivo da instituição; II - ser, preferencialmente, docente de curso de licenciatura; III possuir experiência mínima de três anos no magistério superior; e IV - selecionar os professores supervisores dos bolsistas de iniciação à docência, necessariamente com prática de sala de aula na educação básica (MEC-CAPES-FNDE, 2007, p. 39).

Destaca-se que não havia especificações quanto às competências do Coordenador de Área, exigindo-se apenas que pertencesse ao quadro efetivo da Instituição com, no mínimo, três anos de experiência no Ensino Superior.

Do primeiro edital (2007) até o ano de 2018, houve algumas alterações em alguns aspectos do Programa. Em 2009, é lançada a Portaria no 122 de 16 de setembro de 2009; essa portaria aponta as diretrizes para o PIBID, ampliando sua atuação para outras licenciaturas, assim como para as Instituições Estaduais de Ensino Superior. Insere o Coordenador Institucional e esclarece que as atribuições e os requisitos dos bolsistas serão definidos em edital, segundo as normas da CAPES (CAPES-DEB, 2009).

A Portaria no 72, de 09 de abril de 2010, estende a atuação do PIBID às IES Públicas Municipais e Universidades e Centros Universitários comunitários e confessionais, sem fins lucrativos; dá prioridade às instituições que participaram de programas estratégicos do MEC como o Exame Nacional de Desempenho de Estudantes (ENADE), Programa de Apoio a Planos de Reestruturação e Expansão das Universidades Federais (REUNI) e programas de valorização do magistério (CAPES-DEB, 2010a).

A Portaria no 136, de 01 de julho de 2010, altera a modalidade de aplicação da dotação orçamentária referente ao PIBID, ampliando o orçamento. Essa medida visou o atendimento às Instituições Municipais e Particulares, através de convênios (CAPES-DEB, 2012). 
A Portaria no 260, de 30 de dezembro de 2010, aprova as normas gerais do PIBID, apresentando, de forma mais clara e detalhada, os requisitos e atribuições dos bolsistas, além de incluir o Coordenador de Área de Gestão de Processos Educacionais, responsável por apoiar o Coordenador Institucional no desenvolvimento do projeto institucional (CAPES-DEB, 2010b). Por exemplo, as atribuições do Coordenador de Área estão apresentadas no Quadro 1.

Quadro 1 - Atribuições do Coordenador de Área

I. responder pela coordenação geral do subprojeto de área perante a coordenação institucional; II. fazer um diagnóstico da situação de sua área de conhecimento na rede pública do estado e município;

III. garantir, acompanhar e registrar o planejamento, a organização e a execução das atividades previstas no subprojeto;

IV. constituir e participar de comissões de seleção de bolsistas de iniciação à docência e de Supervisores para atuarem no subprojeto;

V. orientar e acompanhar a atuação dos bolsistas de iniciação à docência, inclusive a frequência às atividades e atuar conjuntamente com os Supervisores das escolas envolvidas, sempre no âmbito do subprojeto que coordena;

VI. apresentar ao Coordenador Institucional relatório anual contendo descrições, análise e avaliação do desenvolvimento do subprojeto que coordena;

VII. manter o Coordenador Institucional informado de toda e qualquer substituição, inclusão ou desistência de Supervisores, bem como de bolsistas de iniciação à docência de sua área;

VIII. elaborar relatórios sobre o subprojeto, informando sobre a participação dos Supervisores, repassando-os ao Coordenador Institucional do projeto;

IX. garantir a capacitação dos Supervisores nas normas e nos procedimentos do PIBID bem como sua participação em eventos e em atividades de formação dos futuros docentes, assegurando-Ihes oportunidades de desenvolvimento profissional;

X. realizar o acompanhamento técnico-pedagógico do subprojeto sob sua coordenação;

XI. participar de reuniões e seminários locais e regionais do Programa Institucional de Bolsa de Iniciação à Docência (PIBID), realizando todas as atividades previstas, tanto presenciais quanto à distância, quando convocados; e

XII. enviar ao Coordenador Institucional do projeto documentos de acompanhamento das atividades dos bolsistas de iniciação à docência sob sua orientação, sempre que solicitado.

Fonte: CAPES-DEB (2010b, p. 8)

Analisando-se o Quadro 1, percebe-se que o Coordenador de Área é responsável pelo planejamento das atividades dentro e fora da escola e pela articulação das ações do subprojeto nos dois espaços, universidade e escola, as quais envolvem três atores, o Coordenador de Área, o licenciando-bolsista e o supervisor. Nesse sentido, o Coordenador de Área tem um papel importante na definição das ações e procedimentos do subprojeto que coordena.

A importância do Coordenador na gestão dos subprojetos PIBID também foi identificada em outros estudos (PEREIRA et al., 2020). Por exemplo, Reis (2017) identificou a importância da gestão do Coordenador em seu estudo, desvelando que o Coordenador de Área tem um papel predominante nas 
atividades desenvolvidas, por exemplo, mediando discussões entre os licenciandos bolsistas e impulsionando o desenvolvimento das atividades e das reflexões advindas do processo de elaboração e aplicação das atividades educativas. Inclusive, a gestão do Coordenador é validada pelo envolvimento dos licenciandos bolsistas com as atividades propostas pois, para eles, o desenvolvimento das atividades está diretamente relacionado à forma como o coordenador conduz o percurso formativo no programa que coordena (SILVA, 2015b).

É de se esperar que as ações do Coordenador de Área desenvolvidas no âmbito de projetos PIBID o façam refletir sobre sua própria atuação docente no Ensino Superior, especialmente, as atribuições ii, iii, v, x e xi (Quadro 1), referentes à ação do Coordenador de Área na gestão do PIBID e na articulação entre universidade e escola.

Estudos envolvendo mais de dois mil depoimentos, questionários e relatórios anuais dos Coordenadores de área do PIBID enviados para a DEB apontam que esse programa tem proporcionado aos Coordenadores de Área oportunidades de desenvolvimento profissional (CAPES-DEB, 2012; 2013b, 2014). Segundo os próprios Coordenadores de Área, ter coordenado projetos PIBID possibilitou-lhes i) a oportunidade de desenvolvimento profissional; ii) a elevação da auto-estima e reconhecimento entre os pares; iii) o diálogo com as escolas; iv) a revisão dos projetos pedagógicos das disciplinas ofertadas nas Universidades; v) empregar novas linguagens e tecnologias da informação e comunicação, e incentivar a inovação das ações de formação de professores; e vi) a produção, publicação e apresentação de estudos científicos sobre formação de professores.

A Portaria no 96, de 18 de julho de 2013, estabelece novas normas para o PIBID, visando regulamentar a ação do programa. Na nova configuração, podem participar, além das instituições já mencionadas, as instituições de direito privado que têm como público alunos do Programa Universidade para Todos (PROUNI; CAPES-DEB; 2010a). Este é um ponto crítico com relação ao público-alvo do PIBID, que inicialmente atendia apenas IES Federais, foi, progressivamente, tendo seu escopo ampliado até contemplar instituições de 
direito privado. Em 2014, as instituições de direito privado respondiam por 18\% das concessões do PIBID, o que correspondia a $47 \%$ das IES contempladas (GIMENES, 2016). Este dado mostra que as instituições públicas e confessionais implementavam maior número de programas PIBID, que contemplavam a maioria dos bolsistas licenciandos, mostrando que cada uma das instituições de direito privado respondia por um reduzido número de programas PIBID, sugerindo que a inserção de seus licenciandos no PIBID tenha sido relativamente pouco expressiva.

Ainda, há duas portarias mais. A primeira delas é a Portaria no 46, de 11 de abril de 2016, que muda o regulamento do PIBID na tentativa de agrupá-lo a outros programas que visam à melhoria da qualidade da Educação Básica. Porém, houve resistência das Universidades, pois essa nova configuração descaracterizava o PIBID, ao priorizar o reforço escolar e a melhoria dos índices de aprendizagem em detrimento da formação do licenciando. Assim, a Portaria no 46 é revogada pela Portaria no 84, de 15 de junho de 2016 (CAPESDEB, 2016a; 2016b).

A Portaria no 175, de 7 de agosto de 2018, regulamenta a concessão de bolsas e o regime de colaboração no âmbito do Programa de Residência

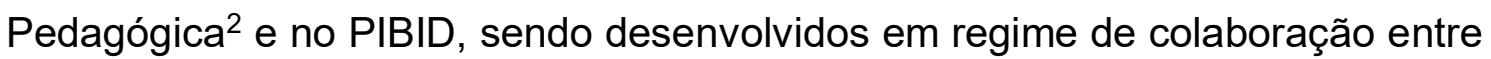
o Governo Federal (por meio da CAPES), Estados e municípios (CAPES-DEB, 2018b). Essa é a portaria em que houve um número maior de modificações quanto às especificidades do PIBID. Dentre as principais modificações está a retirada do Coordenador de Área, do Coordenador de Área de Gestão de Processos Educacionais, a ampliação do público-alvo para o Sistema Universidade Aberta do Brasil (UAB), a limitação a 45 mil bolsas ${ }^{3,4}$, o limite de

\footnotetext{
2 O Programa de Residência Pedagógica foi instituído por meio da Portaria no 38 , de 28 de fevereiro de 2018. A implementação deste programa teve como objetivo dar apoio às IES na implementação de projetos que estimulem a articulação entre teoria e prática nos cursos de Licenciatura. Para tanto, o programa concede bolsas para o Residente, Coordenador Institucional, Docente Orientador e o Preceptor. O Residente é o licenciando matriculado em curso de licenciatura e que tenha cursado no mínimo $50 \%$ do curso, o Coordenador Institucional é o docente da IES responsável pelo projeto institucional de Residência Pedagógica, o Docente Orientador é o docente que orientará o estágio dos residentes estabelecendo a relação entre teoria e prática e, o Preceptor, é o professor da escola de educação básica que acompanhará os residentes na escola-campo (CAPES-DEB, 2018a).

3 Outras 45 mil bolsas foram disponibilizadas para o Programa de Residência Pedagógica (CAPES-DEB, 2018d).
} 
até 350 IES, a obrigatoriedade do bolsista licenciando estar matriculado na primeira metade do curso de Licenciatura (discente que não tenha concluído mais de $60 \%$ da carga horária regimental do curso), a limitação em até 18 meses para a permanência do bolsista licenciando e a possibilidade institucionalizada da participação do licenciando sem a contrapartida da bolsa (CAPES-DEB, 2018b, 2018c).

Constata-se que, embora os objetivos sofressem poucas mudanças, houve diversas alterações na organização e estrutura do PIBID, como sumariado no Quadro 2.

As alterações foram justificadas pelo expressivo crescimento do Programa e sua modificação, de política de governo, para política de Estado, pela Lei 12.796, de abril de 2013, que insere o PIBID como uma das políticas da Lei de Diretrizes e Bases da Educação Brasileira (LDB), um novo marco para o programa (CASA CIVIL, 2013). O Quadro 2 mostra que o PIBID ainda incentiva a formação de professores para a Educação Básica e a valorização do magistério, visando promover a melhoria da qualidade da Educação Básica, como previsto quando de sua implementação pela Portaria Normativa no 38 , de 12 de dezembro de 2007, permanecendo na Portaria no 96, de 18 de julho de 2013 e na atual Portaria no 175 de 7 de agosto de 2018, a qual detalha ações mais específicas, pertinentes à aprendizagem da docência (CAPES-DEB, 2013a; MEC-CAPES-FNDE, 2007). Este conjunto de dados mostra que as modificações inicialmente buscavam a consolidação e expansão do PIBID. Entretanto, a partir de 2013, foram, paulatinamente , implementadas alterações que conduziram a perdas para o Programa, que o vêm descaracterizando como uma política pública de incentivo à formação de professores para a escola básica, dentre outras a limitação de tempo de participação dos licenciandos.

\footnotetext{
${ }^{4}$ Em 2007, foram disponibilizadas 3.088 bolsas. Até 2013, há um crescimento de cerca de 30 vezes na abrangência do programa, quando são implementadas 90.254 bolsas. O PIBID sofre uma redução de bolsas, em 2014, para 81.993, em 2016, para 73.300 bolsas e, em 2018, há uma limitação do número de bolsas para, no máximo, 45 mil (CAPES-DEB, 2018c, 2014; CAPES-MEC, 2017; 2016). Em 2014, das 316 IES contempladas com um ou mais programas da DEB, o PIBID esteve presente em 313 (havendo uma limitação de até 350 IES no Edital de 2018; CAPES-DEB, 2018c), o que indica seu potencial como indutor para a formação de professores (CAPES-DEB, 2014).
} 
Quadro 2 - Comparação entre aspectos das Portarias 2007, 2013 e 2018

\begin{tabular}{|c|c|c|c|}
\hline & \multicolumn{3}{|c|}{ Portaria } \\
\hline Número: data & 38: 12/12/ 2007 & 96: 18/07/2013 & 175: 07/08/2018 \\
\hline Projeto & Não existe limitação & 1 por IES & 1 por IES \\
\hline Subprojeto & Não existe limitação & $\begin{array}{l}1 \text { por licenciatura } \\
\text { em cada campus } \\
\text { além dos os } \\
\text { interdisciplinares }\end{array}$ & Mantido \\
\hline $\begin{array}{l}\text { Coord. } \\
\text { Institucional }\end{array}$ & Não consta & 1 por projeto & $\begin{array}{lr}1 \quad \text { por } & \text { projeto, } \\
\text { especifica } & \text { a } \\
\text { competência } \\
\text { técnica }\end{array}$ \\
\hline $\begin{array}{ll}\text { Coord. } & \text { de } \\
\text { Gestão } & \end{array}$ & Não consta & 1 por projeto & Não consta \\
\hline Coord. de Área & $\begin{array}{l}\text { Não existe limitação, } \\
\text { não especifica a } \\
\text { competência técnica }\end{array}$ & $\begin{array}{l}\text { Mínimo de } 1 \text { por } \\
\text { subprojeto; requer } \\
\text { competência } \\
\text { técnica }\end{array}$ & 1 por subprojeto \\
\hline Prof. Supervisor & Não existe limitação & $\begin{array}{l}\text { Mínimo de } 1 \text { por } \\
\text { subprojeto }\end{array}$ & 3 por subprojeto \\
\hline $\begin{array}{l}\text { Bolsista } \\
\text { Licenciando }\end{array}$ & Não existe limitação & $\begin{array}{l}\text { Mínimo de } 5 \text { por } \\
\text { subprojeto }\end{array}$ & $\begin{array}{lr}\text { Mínimo de } 24 \text { e } \\
\text { máximo de } 30 \text { por } \\
\text { subprojeto, } & \text { dos } \\
\text { quais até } & 6 \\
\text { voluntários } & \end{array}$ \\
\hline Licenciaturas & $\begin{array}{l}\text { Preferência: } \quad \text { Física, } \\
\text { Química, } \\
\text { Matemática } \\
\text { Biologia }\end{array}$ & $\begin{array}{l}\text { Atende a todas as } \\
\text { Licenciaturas }\end{array}$ & $\begin{array}{l}\text { Atende a todas as } \\
\text { Licenciaturas }\end{array}$ \\
\hline Escolas & $\begin{array}{l}\text { Com baixos índices } \\
\text { no IDEB ou baixas } \\
\text { médias no ENEM }\end{array}$ & $\begin{array}{l}\text { Baixos índices no } \\
\text { IDEB ou } \\
\text { experiências bem- } \\
\text { sucedidas }\end{array}$ & $\begin{array}{l}\text { Da Rede Pública } \\
\text { de Ensino }\end{array}$ \\
\hline
\end{tabular}

Fonte: elaborado pelos autores

Neste sentido, observa-se a necessidade de se discutir e investigar o possível impacto que as alterações mencionadas possam ter na formação inicial e continuada de professores. No próximo tópico, serão apresentados resultados sobre a potencialidade do PIBID para o desenvolvimento profissional de Coordenadores de Área.

\section{A formação do Coordenador de Área no âmbito do PIBID}

$\mathrm{Na}$ literatura especializada, há expressivo número de pesquisas sobre a formação docente no âmbito do PIBID, embora poucas investiguem a contribuição deste programa para a formação dos Coordenadores de Área (PEREIRA et al., 2020; MASSENA, 2013). Em algumas das pesquisas 
identificadas, a formação do Coordenador de Área no âmbito do PIBID foi o tema de investigação, enquanto outras pesquisas buscaram investigar, também, a formação dos diversos atores participantes deste projeto.

Silva (2015a) investigou os impactos da participação no PIBID sobre o desenvolvimento profissional de 11 Coordenadores de Área de projetos PIBIDFísica. Para a obtenção das informações, realizaram-se entrevistas semiestruturadas. A análise das entrevistas possibilitou a criação de quatro categorias: i) a parceria universidade-escola, referindo-se à oportunidade do Coordenador de Área conhecer a realidade da escola de Educação Básica; ii) as articulações com a pesquisa, a aproximação com o contexto escolar e a busca de soluções para problemas enfrentados na Educação Básica fundamenta as pesquisas acadêmicas no âmbito do PIBID; iii) a relação com a instituição universitária, referindo-se tanto ao trabalho colaborativo com os demais docentes da instituição como aos resultados que o PIBID proporciona para os cursos de Licenciatura, por exemplo, modificação de disciplinas e da estruturação do curso; e iv) os impactos na prática deste docente como formador de professores, pois coordenar projetos PIBID possibilita adquirir conhecimentos e viver situações que incentivam reflexões sobre a própria prática, o que repercute tanto nas ações de ensino em sala de aula, como na modificação dos currículos das Licenciaturas.

Em síntese, os resultados mostram que a coordenação dos subprojetos PIBID possibilita que esses sujeitos reflitam sobre sua formação e sobre a formação dos licenciandos, o que resulta na transformação de suas práticas formativas com base nessas reflexões. Assim, suas práticas refletem resultados obtidos por meio das ações do PIBID tanto em suas pesquisas como no próprio curso de Licenciatura.

O trabalho colaborativo fomentado pelo PIBID também foi identificado em outras pesquisas (PEREIRA et al., 2020; SANTOS; ARROIO, 2015), as quais mostram que esta característica advém da dinâmica e estrutura dos projetos PIBID, pautados em atividades de discussão, trocas de experiências e saberes entre licenciandos bolsistas, supervisores e Coordenadores de Área (SANTOS; ARROIO, 2015). Nessa dinâmica, supervisores e Coordenadores de 
Área mobilizam diferentes saberes: os supervisores mobilizam, principalmente, os saberes experienciais do contexto escolar e suas problemáticas, enquanto os Coordenadores de Área atuam, principalmente, auxiliando os licenciandos bolsistas a compreenderem as vivências na escola e a prepararem atividades fundamentando-se na literatura especializada acerca do ensino de Ciências (PEREIRA et al., 2020).

Receputi (2019) investigou as representações sobre "experimentação" de 275 formadores de professores de Química, participantes, ou não, de projetos PIBID-Química. Para a obtenção das informações, empregou um questionário semiestruturado. A análise dos resultados mostra que ter coordenado projetos PIBID-Química contribui para o processo de recontextualização sobre o objeto social "experimentação" pois, embora tanto Coordenadores de Área como não-Coordenadores relacionem a experimentação a aspectos educacionais, vinculando-a à formação de professores de Química, as representações desses dois grupos são distintas: enquanto os Coordenadores do PIBID tendem a relacionar o desenvolvimento das atividades experimentais ao contexto escolar, levando em consideração as particularidades e problemáticas desse espaço, os não-Coordenadores tendem a privilegiar no desenvolvimento das atividades experimentais, no contexto do Ensino Superior, privilegiando seus aspectos mais técnicos; também se referem ao desenvolvimento de pesquisas. Essas diferenças se deram, principalmente, pelas práticas desenvolvidas no âmbito do subprojeto PIBIDQuímica, as quais aproximam o Coordenador da realidade da escola da Educação Básica, modificando suas percepções sobre esse contexto e sobre sua atuação na formação dos futuros professores, contribuindo para reelaboração de sua concepção sobre o ensino e a prática docente.

Pereira, Receputi e Rezende (2020) relatam as contribuições do PIBID para a formação continuada de uma Coordenadora de Área de um subprojeto PIBID-Química. Para tanto, realizaram entrevistas com a Coordenadora, buscando identificar as contribuições desse projeto tanto para sua formação como para a formação dos licenciandos bolsistas. Os resultados mostram que, para esta Coordenadora, o PIBID contribuiu para sua formação continuada, 
trazendo reflexões sobre as problemáticas vivenciadas por docentes e discentes na Educação Básica. Isso só foi possível porque as ações desenvolvidas no âmbito do PIBID tinham como base a realidade escolar. A vivência da Coordenadora no PIBID também possibilitou a criação de uma disciplina para o curso de Licenciatura em Química ao qual a professora está vinculada e de um curso de extensão para professores da Educação Básica, ambos versando sobre interdisciplinaridade. A Coordenadora entrevistada comenta que tanto o curso como a disciplina têm contribuído para a formação inicial dos licenciandos e para a formação continuada dos professores da Educação Básica na região onde se situa a Instituição de Ensino Superior.

Outros estudos investigaram a contribuição do PIBID para a formação tanto dos Coordenadores de Área como dos licenciandos bolsistas ou, ainda, dos supervisores das escolas de Ensino Básico.

Por exemplo, Gatti e colaboradores (2014) realizaram um estudo amplo com o objetivo de compreender melhor o papel do PIBID, pela análise qualitativa de respostas a questionários contendo questões abertas e de múltipla escolha, que foram disponibilizadas on-line pela CAPES para Supervisores, Coordenadores de Área, Coordenadores Institucionais e licenciandos Bolsistas. A análise das respostas de 1.486 Coordenadores de Área mostra que eles consideram que o PIBID contribui para sua formação continuada em vários aspectos: i) aproximando-os da realidade do contexto escolar da Educação Básica; ii) contribuindo para a modificação de posturas em relação ao curso de Licenciatura; iii) fomentando o questionamento da qualidade das práticas formativas no âmbito da docência na própria IES; e iv) favorecendo o desenvolvimento de novas compreensões sobre educação, escola e práticas educativas.

Rabelo e Coelho (2018) investigaram a contribuição do PIBID na formação inicial dos licenciandos bolsistas e na formação continuada da Coordenadora de Área de um projeto PIBID-Biologia. Para tanto, realizaram entrevistas narrativas com os atores nele envolvidos. Quanto à Coordenadora de Área, os resultados mostram que a participação no projeto possibilitou que refletisse, reavaliasse e modificasse suas práticas pedagógicas, o que 
contribuiu para seu desenvolvimento profissional e para a reconstrução de sua identidade docente. A Coordenadora entrevistada comenta que ter coordenado o PIBID a aproximou da realidade escolar e dos problemas vivenciados pelos professores na Educação Básica. Isso a fez aprofundar-se na literatura sobre ensino de Ciências, influenciando, inclusive, suas aulas na graduação.

Lira (2016) investigou a contribuição do projeto PIBID-Química na construção de práticas docentes de bolsistas licenciandos, supervisores e Coordenadores de Área. Em relação aos Coordenadores, foram aplicados questionários e realizadas entrevistas semiestruturados com dois Coordenadores de Área buscando desvelar, dentre vários outros aspectos, suas percepções sobre as contribuições do PIBID para sua formação continuada. Os resultados do estudo mostram que os Coordenadores de Área entendem que o PIBID tem contribuído para sua formação continuada, principalmente por aproximá-los do contexto da Educação Básica, levando à reflexão sobre a formação inicial dos licenciandos bolsistas e continuada dos supervisores.

Em síntese, os resultados destas pesquisas mostram que participar como Coordenador de Área em projetos PIBID contribui, dentre outros aspectos, para o desenvolvimento profissional do docente, pois possibilita a recontextualização dos conhecimentos específicos da área, além de favorecer o desenvolvimento de novas compreensões sobre educação, escola e práticas educativas, influenciando tanto a dinâmica do PIBID como os cursos de licenciatura, além de fomentar pesquisas científicas sobre as problemáticas vivenciadas.

Em síntese, a análise deste conjunto de estudos indica que as mudanças na percepção dos Coordenadores de Área sobre o processo de ensino e aprendizagem e a escola básica resulta, principalmente, do trabalho colaborativo realizado com os supervisores e licenciandos bolsistas, além do conhecimento obtido sobre a realidade das escolas da Educação Básica, devido às ações desenvolvidas no PIBID, que buscam superar os problemas enfrentados na Educação Básica, requerendo estudo, discussão e reflexão 
sobre as estratégias que serão adotadas. Estas ações contribuem para o desenvolvimento profissional da Coordenador.

\section{Considerações Finais}

Este artigo, por meio da análise conceitual, contextual e investigativa, possibilitou identificar as relações entre o desenvolvimento profissional dos professores do Ensino Superior e a coordenação de projetos PIBID.

A análise conceitual possibilitou compreender a necessidade da implementação de programas que levem ao desenvolvimento profissional dos professores do Ensino Superior. Esses programas devem contribuir tanto para a sensibilização acerca das especificidades da Educação e do ensino, como para o desenvolvimento de conhecimentos e saberes didático-pedagógicos específicos.

A análise contextual desvelou os meandros da construção do PIBID, possibilitando compreender as ações e atribuições dos Coordenadores de Área, responsáveis pelo planejamento das atividades dentro e fora da escola e pela articulação das ações do subprojeto nos dois espaços, universidade e escola.

A análise investigativa, por sua vez, mostra as principais contribuições do PIBID para o desenvolvimento profissional dos Coordenadores de Área. O desenvolvimento profissional é fomentado pelo trabalho colaborativo entre os atores do PIBID, o qual tem como principal ação a superação dos vários problemas enfrentados no contexto escolar.

Por fim, ressalta-se a preocupação com relação às diversas alterações que o PIBID vem sofrendo, por exemplo, a inclusão de Instituições de Ensino Superior de direito privado, a redução de bolsas, a limitação na participação dos licenciandos no PIBID em até aos primeiros dois anos do curso de Licenciatura e por um período de, no máximo, 18 meses, e a possibilidade institucionalizada da participação do licenciando sem a concessão de bolsa. Essas alterações certamente têm consequências para a formação inicial e continuada dos professores e, portanto, para a qualidade da Educação Básica. 


\section{Agradecimento}

O presente trabalho foi realizado com apoio da Coordenação de Aperfeiçoamento de Pessoal de Nível Superior - Brasil (CAPES). Código de financiamento 001.

\section{Referências}

ANDRÉ, M. E. D. A. A produção acadêmica sobre formação de professores: um estudo comparativo das dissertações e teses defendidas nos anos de 1990 e 2000. Formação Docente, v. 1, n. 1, p. 41-56. 2009.

ARROIO, A.; HONÓRIO, K. M.; HOMEM-DE-MELO, P.; WEBER, K. C.; SILVA, A. B. F. A prática docente na formação do pós-graduando em química. Química Nova, São Paulo, v. 31, n. 7, p. 1888-1891, 2008.

BARDIN, L. Análise de conteúdo. Lisboa: Edições 70, 2011.

CAPES. Portaria no 52, de 26 de setembro de 2002. Dispõe sobre a aprovação do regulamento para o Programa de Demanda Social. Disponível em:

$<$ https://novo.poli.usp.br/wpcontent/uploads/2010/03/download relatorios Portaria 52 Regulamento DS.p df>. Acesso em: 08 set. 2020.

CAPES-DEB. Relatório de Gestão PIBID 2009-2011. Brasília: Diretoria de Formação de Professores da Educação Básica - DEB. Brasília. 2012. Disponível em:

<http://www.capes.gov.br/images/stories/download/bolsas/RelatorioGestaoOBE DUC-2009-2011 27jul12.pdf>. Acesso em: 08 set 2020.

CAPES-DEB. Relatório de Gestão PIBID 2009-2013. Brasília: Diretoria de Formação de Professores da Educação Básica - DEB. Brasília. 2013b. Disponível em:

<http://www.capes.gov.br/images/stories/download/bolsas/1892014-relatorioPIBID.pdf>. Acesso em: 08 set 2020.

CAPES-DEB. Relatório de Gestão 2009-2014. Brasília: Diretoria de Formação de Professores da Educação Básica - DEB. Brasília. 2014. Disponível em: $<$ https://capes.gov.br/images/stories/download/bolsas/20150818 DEB-relatoriode-gestao-vol-1-com-anexos.pdf>. Acesso em: 08 set 2020.

CAPES-DEB. Portaria Normativa no 122, de 16 de setembro de 2009. Dispõe sobre o PIBID - Programa Institucional de Bolsa de Iniciação à Docência, no âmbito da CAPES. Brasília: Ministério da Educação. 2009. Disponível em: 
$<$ http://www.capes.gov.br/images/stories/download/bolsas/PortariaNormativa12 2 PIBID.pdf>. Acesso em: 08 set 2020.

CAPES-DEB. Portaria no 72, de 09 de abril de 2010. Dá nova redação a Portaria que dispõe sobre o Programa Institucional de Bolsa de Iniciação à Docência - PIBID, no âmbito da CAPES. Brasília. Diário Oficial da União, n. 62, seção 1, p. 26-27, 2010a. Disponível em:

$<$ https://capes.gov.br/images/stories/download/legislacao/Portaria72 Pibid 090 410.pdf>. Acesso em: 08 set 2020.

CAPES-DEB. Portaria no 260, de 30 de dezembro de 2010. Aprova as normas do Programa Institucional de Bolsa de Iniciação à Docência - PIBID. Brasília. 2010b. Disponível em:

<https://www.capes.gov.br/images/stories/download/legislacao/Portaria260 PIB ID2011 NomasGerais.pdf>. Acesso em: 08 set 2020.

CAPES-DEB. Portaria no 96 de 18 de julho de 2013. Aprova as novas normas do Programa Institucional de Bolsa de Iniciação à Docência - PIBID. Brasília. 2013a. Disponível em:

$<$ https://www.capes.gov.br/images/stories/download/legislacao/Portaria 0961 8jul13 AprovaRegulamentoPIBID.pdf>. Acesso em: 08 set 2020.

CAPES-DEB. Portaria no 46 de 11 de abril de 2016. Aprova o Regulamento do Programa Institucional de Bolsa de Iniciação à Docência - Pibid. Brasília. 2016a. Disponível em:

$<$ https://www.capes.gov.br/images/stories/download/legislacao/15042016Portaria-46-Regulamento-PIBID-completa.pdf>. Acesso em: 08 set 2020.

CAPES-DEB. Portaria no 84 de 15 de junho de 2016. Revoga a Portaria no 46, de 11 de abril de 2016. Brasília. Diário Oficial da União, n. 113, seção 1, p. 19, 2016b. Disponível em:

<https://capes.gov.br/images/stories/download/legislacao/15062016-

Revogacao-da-Portaria-n-46-2016.pdf>. Acesso em: 08 set 2020.

CAPES-DEB. Portaria no 38, de 28 de fevereiro de 2018. Institui o Programa de Residência Pedagógica. Brasília. Diário Oficial da União, n. 41, Seção 1, pág. 28, 2018a. Disponível em:

$<$ https://capes.gov.br/images/stories/download/legislacao/01032018-portaria-n38-de-28-02-2018-residencia-pedagogica.pdf>. Acesso em: 08 set 2020.

CAPES-DEB. Portaria CAPES no 175 de 7 de Agosto de 2018. Altera 0 Anexo I da Portaria no 45, de 12 de março de 2018. Brasília. 2018b. Disponível em:<http://capes.gov.br/images/stories/download/legislacao/09082018-

Portaria 175 Altera Portaria 45 de 2018.pdf>. Acesso em: 08 set 2020.

CAPES-DEB. Edital CAPES no 07/2018. 2018c. Disponível em: 
$<$ https://www.capes.gov.br/images/stories/download/editais/01032018-Edital-72018-PIBID.pdf>. Acesso em: 08 set 2020.

CAPES-DEB. Edital CAPES no 06/2018. 2018d. Disponível em: $<$ https://www.capes.gov.br/images/stories/download/editais/01032018-Edital-62018-Residencia-pedagogica.pdf>. Acesso em: 08 set 2020.

CAPES-MEC. Relatório de Gestão de Exercício de 2015. Brasília: Ministério da Educação - MEC, 2016. Disponível em:

$<$ http://www.capes.gov.br/images/stories/download/Contas Publicas/2015 Rel atorio de Gestao.pdf>. Acesso em: 08 set 2020.

CAPES-MEC. Relatório de Gestão de Exercício de 2016. Brasília: Ministério da Educação - MEC, 2017. Disponível em:

$<$ https://capes.gov.br/images/stories/download/acessoainformacao/Relatorio d e Gestao CAPES 2016.pdf>. Acesso em: 08 set 2020.

CASA CIVIL. Lei no 12.796, de 4 de abril de 2013. Altera a Lei no 9.394, de 20 de dezembro de 1996, que estabelece as diretrizes e bases da educação nacional, para dispor sobre a formação dos profissionais da educação e dar outras providências. 2013. Disponível em:

<http://www.planalto.gov.br/CCIVIL 03/ Ato2011-2014/2013/Lei/L12796.htm>. Acesso em: 08 set 2020.

CHAMLIAN, H. C. Docência na universidade: professores inovadores na USP. Cadernos de Pesquisa. n. 118, p. 41-64, 2003.

CHAUI, M. A universidade pública sob nova perspectiva. Revista Brasileira de Educação, n. 24, p. 5-15, 2003.

CORDEIRO, A. M.; OlIVEIRA, G. M.; RENTERÍA, J. M.; GUIMARÃES, C. A. Revisão sistemática: uma revisão narrativa. Revista do Colégio Brasileiro de Cirurgiões, v. 34, n. 6, p. 428-431, 2007.

CRUZ, G. B. D. Didática e docência no ensino superior. Revista Brasileira de Estudos Pedagógicos, v. 98, n. 250, p. 672-689, 2017.

FREIRE, L. I. F.; FERNANDEZ, C. O professor universitário novato: tensões, dilemas e aprendizados no início da carreira docente. Ciência \& Educação, v.21, n.1, p.255-272, 2015.

GATTI, B.; ANDRÉ, M.; GIMENES, N.; FERRAGUT, L. Um estudo avaliativo do Programa Institucional de Bolsa de Iniciação à Docência (Pibid). São Paulo: FCC, 2014.

GIMENES, C. I. O Programa Institucional de Bolsa de Iniciação à Docência (PIBID) e a formação de professores de Ciências Naturais: possibilidade para a práxis na formação inicial? 2016. 247f. Tese (Doutorado em Educação) - Faculdade de Educação, Universidade de São Paulo, SP, 2016. 
HERMANOWICZ, J. C. Faculty perceptions of their graduate education. Higher Education, v. 72, n. 3, p 291-305, 2015.

JUNGES, K. S.; BEHRENS, M. A. Uma formação pedagógica inovadora como caminho para a construção de saberes docentes no Ensino Superior. Educar em Revista, n. 59, p. 211-229, 2016.

LIRA, F. L. C. O PIBID e a construção da prática docente do curso de licenciatura em Química da Universidade Federal de Alagoas: concepção, contribuição e interação. 2016. 131 f. Dissertação (Mestrado em Educação) Universidade Tiradentes, UNIT, 2016.

MALDANER, O. A.; ZANON, L. B.; AUTH, M. A. Pesquisa sobre educação em ciências e formação de professores. In. A pesquisa em ensino de ciências no Brasil e suas metodologias. Org. SANTOS, F. M. T. GRECA, I. M. - ljui: Ed. Unijuí, 2006, p. 49-88.

MASSENA, E. P. Avaliando a produção científica em torno do PIBID: tendências, relevâncias e silenciamentos. In IX Encontro Nacional de Pesquisa em Educação em Ciências, 2013, Águas de Lindóia. Anais [...] IX Encontro Nacional de Pesquisa em Educação em Ciências, 2013.

MEC-CAPES-FNDE. Edital MEC/CAPES/FNDE: seleção pública de propostas de projetos de iniciação à docência voltados ao programa institucional de iniciação à docência - pibid. 2007. Disponível em:

<https://www.capes.gov.br/images/stories/download/editais/Edital PIBID.pdf>.

Acessado em 30 de abril de 2019.

OLIVEIRA JÚNIOR, A. P.; PRATA-LINHARES, M. M. P.; KARWOSKI, A. M. Formação docente no contexto brasileiro das instituições federais de educação superior. Ensaio: Avaliação e Políticas Públicas em Educação, v. 26, n. 98, p. 52-90, 2018.

PEREIRA, T. M., RECEPUTI, C. C.; MARAGLIA, P. H.; VOGEL, M.; REZENDE, D. B. Contribuições do PIBID para a formação inicial de licenciandos em Química: análise de Teses e Dissertações. Química Nova na Escola, v. 42, n. 1, p. 56-67, 2020.

PEREIRA, T. M., RECEPUTI, C. C.; REZENDE, D. B. Potencialidade do PIBID para além da formação de seus bolsistas: relatos de uma coordenadora. História Oral, v. 23, n. 1, p. 77-91, 2020.

QUADROS, A. L.; SILVA, D. C.; SILVA, F. C.; SILVA, G. F.; OLIVEIRA, S. R.; ANDRADE, F. P.; TRISTÃO, J. C.; SANTOS L. J.; ALEME, H. G. Professor de ensino superior: o entendimento a partir de narrativas de pós-graduandos em química. Educação e Pesquisa, v. 38, n. 2, p. 389-402, 2012.

RABELO, D. B. B.; COELHO, G. R. As contribuições do Programa Institucional de bolsa de iniciação à Docência (PIBID) do subprojeto de Biologia da UFES para a profissionalização docente de seus bolsistas e formação continuada do 
Coordenador de Área. Investigações em Ensino de Ciências, v. 23, n, 2, p. 190-210, 2018.

RECEPUTI, C. C. Percepções de Professores de Licenciaturas em Química sobre "experimentação", na perspectiva da Teoria das Representações Sociais. 2019. 134 f. (Dissertação) Programa de Pós-Graduação Interunidades em Ensino de Ciências, Universidade de São Paulo, SP, 2019.

REIS, N. A. Abordagem contextual no âmbito do processo formativo do PIBID. 2017. 143 f. Dissertação (Mestrado em Ensino de Ciências e Matemática) - Universidade Federal de Sergipe, UFS, 2017.

SILVA, F. L. Coordenadores de área do PIBID: um olhar sobre o desenvolvimento profissional. 2015. 154f. (Dissertação). Programa de PósGraduação Interunidades em Ensino de Ciências, Universidade de São Paulo, SP. 2015a.

SILVA, G. G. Significações do PIBID à formação para a docência na percepção de licenciandos em Ciências da Natureza/Química do IF-SC/SJ. 2015. 136 f. Dissertação (Mestrado em Ensino de Ciências) - Universidade Federal de Santa Catarina, UFSC, 2015b.

SILVA, O. B.;QUEIROZ, S. L. Produção acadêmica sobre a formação de professores de química no Brasil: focos temáticos das dissertações e teses defendidas no período de 2001 a 2010. Alexandria, Revista de Educação em Ciência e Tecnologia, v. 10, n. 1., p. 271-304, 2017.

ZANCHET, B. M. B. A; FELDKECHER, N. Inserção e desenvolvimento profissional de docentes universitários iniciantes: necessidades de espaços de discussão pedagógica. Acta Scientiarum. Education, v. 38, n. 1, p. 93-102, 2016.

ZANON, D. A. V.; OLIVEIRA, J. R. S.; QUEIROZ, S. L. O "saber" e o "saber fazer" necessários à atividade docente no ensino superior: visões de alunos de pós-graduação em Química. Ensaio Pesquisa em Educação em Ciências, v.11, n.1, p.140-159, 2009.

\section{Sobre os autores}

\section{Caian Cremasco Receputi}

caian.receputi@gmail.com

Mestre em Ensino de Ciências pelo Programa de Pós-Graduação Interunidades em Ensino de Ciências da Universidade de São Paulo (PIEC-USP). Doutorando no PIEC-USP. Membro do Grupo de Pesquisa Linguagem no Ensino de Química (LiEQui). 


\section{Daisy de Brito Rezende}

dbrezend@gmail.com

Doutora em Química Orgânica pela Universidade de São Paulo (USP). Professora Doutora do Departamento de Química Fundamental da USP. Orientadora plena do Programa de Pós-graduação Interunidades em Ensino de Ciências da Universidade de São Paulo (USP). Líder do Grupo de Pesquisa Linguagem no Ensino de Química (LiEQui).

\section{APÊNDICE A - Referências legais sobre o PIBID}

\begin{tabular}{|c|c|}
\hline Referências Legais & Assunto \\
\hline $\begin{array}{l}\text { Edital MEC/CAPES/FNDE } \\
\text { de } 2007 .\end{array}$ & $\begin{array}{l}\text { Seleção pública de propostas de projetos de iniciação à docência } \\
\text { voltados ao programa institucional de iniciação à docência - } \\
\text { PIBID. }\end{array}$ \\
\hline Edital CAPES no 06/2018 & $\begin{array}{l}\text { Chamada Pública para apresentação de propostas no âmbito do } \\
\text { Programa de Residência Pedagógica. }\end{array}$ \\
\hline Edital CAPES no 07/2018. & $\begin{array}{l}\text { Chamada Pública para apresentação de propostas no âmbito do } \\
\text { PIBID. }\end{array}$ \\
\hline $\begin{array}{l}\text { Lei o } 12.796 \text {, de } 4 \text { de abril } \\
\text { de } 2013 .\end{array}$ & $\begin{array}{l}\text { Altera a Lei no } 9.394 \text {, de } 20 \text { de dezembro de 1996, que } \\
\text { estabelece as diretrizes e bases da educação nacional, para } \\
\text { dispor sobre a formação dos profissionais da educação e dar } \\
\text { outras providências. }\end{array}$ \\
\hline $\begin{array}{l}\text { Portaria } \mathrm{n}-122 \text {, de } 16 \text { de } \\
\text { setembro de } 2009 \text {. }\end{array}$ & $\begin{array}{l}\text { Dispõe sobre o PIBID - Programa Institucional de Bolsa de } \\
\text { Iniciação à Docência, no âmbito da CAPES. }\end{array}$ \\
\hline $\begin{array}{l}\text { Portaria } \mathrm{n}-72 \text {, de } 09 \text { de } \\
\text { abril de } 2010 \text {. }\end{array}$ & $\begin{array}{l}\text { Dá nova redação a Portaria que dispõe sobre o Programa } \\
\text { Institucional de Bolsa de Iniciação à Docência - PIBID, no âmbito } \\
\text { da CAPES. }\end{array}$ \\
\hline $\begin{array}{l}\text { Portaria no } 260 \text {, de } 30 \text { de } \\
\text { dezembro de } 2010 .\end{array}$ & $\begin{array}{l}\text { Aprova as normas do Programa Institucional de Bolsa de } \\
\text { Iniciação à Docência - PIBID. }\end{array}$ \\
\hline $\begin{array}{l}\text { Portaria } \mathrm{n} \text { - } 96 \text { de } 18 \text { de } \\
\text { julho de } 2013 .\end{array}$ & $\begin{array}{l}\text { Aprova as novas normas do Programa Institucional de Bolsa de } \\
\text { Iniciação à Docência - PIBID. }\end{array}$ \\
\hline $\begin{array}{l}\text { Portaria } \mathrm{n}^{\circ} 46 \text { de } 11 \text { de } \\
\text { abril de } 2016 \text {. }\end{array}$ & $\begin{array}{l}\text { Aprova o Regulamento do Programa Institucional de Bolsa de } \\
\text { Iniciação à Docência - PIBID. }\end{array}$ \\
\hline $\begin{array}{l}\text { Portaria } \mathrm{n}^{\circ} 84 \text { de } 15 \text { de } \\
\text { junho de } 2016 .\end{array}$ & Revoga a Portaria no 46, de 11 de abril de 2016 . \\
\hline $\begin{array}{l}\text { Portaria } \mathrm{n} \text { - } 38 \text {, de } 28 \text { de } \\
\text { fevereiro de } 2018 \text {. }\end{array}$ & Institui o Programa de Residência Pedagógica. \\
\hline $\begin{array}{l}\text { Portaria no } 175 \text { de } 7 \text { de } \\
\text { agosto de } 2018 .\end{array}$ & Altera o Anexo I da Portaria no 45, de 12 de março de 2018. \\
\hline $\begin{array}{l}\text { Relatório de Gestão DEB } \\
\text { e DED 2009-2011. }\end{array}$ & $\begin{array}{l}\text { Relatório de Gestão da Diretoria de Educação Básica Presencial } \\
\text { (DEB) e a Diretoria de Educação a Distância (DED) de } 2009 \text { à } \\
2011 .\end{array}$ \\
\hline $\begin{array}{l}\text { Relatório de Gestão PIBID } \\
2009-2013 .\end{array}$ & Relatório de Gestão do PIBID de 2009 à 2013. \\
\hline $\begin{array}{l}\text { Relatório de Gestão DEB } \\
\text { 2009-2014. }\end{array}$ & $\begin{array}{l}\text { Relatório de Gestão da Diretoria de Educação Básica Presencial } \\
\text { (DEB) de } 2009 \text { à } 2014 .\end{array}$ \\
\hline $\begin{array}{l}\text { Relatório de } \\
\text { CAPES 2015. }\end{array}$ & Relatório de gestão do exercício de 2015 . \\
\hline $\begin{array}{ll}\text { Relatório de } & \text { Gestão } \\
\text { CAPES 2016. } & \\
\end{array}$ & Relatório de gestão do e) \\
\hline
\end{tabular}

Fonte: elaborado pelos autores 


\section{APÊNDICE B - Relação das publicações analisadas sobre o desenvolvimento profissional de professores do ensino superior}

\begin{tabular}{|c|c|}
\hline $\begin{array}{c}\text { Tipo de } \\
\text { Publicação }\end{array}$ & Referência \\
\hline \multirow{8}{*}{$\stackrel{\substack{0 \\
\frac{D}{2}}}{\frac{0}{4}}$} & $\begin{array}{l}\text { FREIRE, L. I. F.; FERNANDEZ, C. O professor universitário novato: tensões, } \\
\text { dilemas e aprendizados no início da carreira docente. Ciência \& Educação, } \\
\text { v. } 21, \text { n.1, p.255-272, } 2015 \text {. }\end{array}$ \\
\hline & $\begin{array}{l}\text { HERMANOWICZ, J. C. Faculty perceptions of their graduate education. Higher } \\
\text { Education, v. } 72 \text {, n. 3, p 29-305, } 2015 \text {. }\end{array}$ \\
\hline & $\begin{array}{l}\text { JUNGES, K. S.; BEHRENS, M. A. Uma formação pedagógica inovadora como } \\
\text { caminho para a construção de saberes docentes no Ensino Superior. Educar } \\
\text { em Revista, n. } 59 \text {, p. } 211-229,2016 \text {. }\end{array}$ \\
\hline & $\begin{array}{l}\text { MALDANER, O. A.; ZANON, L. B.; AUTH, M. A. Pesquisa sobre educação em } \\
\text { ciências e formação de professores. In. A pesquisa em ensino de ciências no } \\
\text { Brasil e suas metodologias. Org. SANTOS, F. M. T. GRECA, I. M. - ljui: Ed. } \\
\text { Unijuí, 2006, p. 49-88. }\end{array}$ \\
\hline & $\begin{array}{l}\text { OLIVEIRA JÚNIOR, A. P.; PRATA-LINHARES, M. M. P.; KARWOSKI, A. M. } \\
\text { Formação docente no contexto brasileiro das instituições federais de educação } \\
\text { superior. Ensaio: Avaliação e Políticas Públicas em Educação, v. 26, n. 98, p. } \\
52-90,2018 \text {. }\end{array}$ \\
\hline & $\begin{array}{l}\text { QUADROS, A. L.; SILVA, D. C.; SILVA, F. C.; SILVA, G. F.; OLIVEIRA, S. R.; } \\
\text { ANDRADE, F. P.; TRISTÂO, J. C.; SANTOS L. J.; ALEME, H. G. Professor de } \\
\text { ensino superior: o entendimento a partir de narrativas de pós-graduandos em } \\
\text { química. Educação e Pesquisa, v. } 38, \text { n. 2, p. } 389-402,2012 \text {. }\end{array}$ \\
\hline & $\begin{array}{l}\text { ZANCHET, B. M. B. A; FELDKECHER, N. Inserção e desenvolvimento } \\
\text { profissional de docentes universitários iniciantes: necessidades de espaços de } \\
\text { discussão pedagógica. Acta Scientiarum. Education, v. 38, n. 1, p. 93-102, } \\
2016 \text {. }\end{array}$ \\
\hline & $\begin{array}{l}\text { ZANON, D. A. V.; OLIVEIRA, J. R. S.; QUEIROZ, S. L. O "saber" e o "saber } \\
\text { fazer" necessários à atividade docente no ensino superior: visões de alunos de } \\
\text { pós-graduação em Química. Ensaio Pesquisa em Educação em Ciências, } \\
\text { v.11, n.1, p.140-159, 2009. }\end{array}$ \\
\hline
\end{tabular}

Fonte: elaborado pelos autores

\section{APÊNDICE C - Relação das publicações analisadas sobre a contribuição do PIBID no desenvolvimento profissional dos Coordenadores de Área}

\begin{tabular}{|c|l|}
\hline $\begin{array}{c}\text { Tipo de } \\
\text { Publicação }\end{array}$ & \multicolumn{1}{|c|}{ Referência } \\
\hline \multirow{3}{*}{$\%$} & $\begin{array}{l}\text { PEREIRA, T. M., RECEPUTI, C. C.; REZENDE, D. B. Potencialidade do } \\
\text { PIBID para além da formação de seus bolsistas: relatos de uma } \\
\text { coordenadora. História Oral, v. 23, n. 1, p. 77-91, 2020. }\end{array}$ \\
\cline { 2 - 3 } & $\begin{array}{l}\text { RABELO, D. B. B.; COELHO, G. R. As contribuições do Programa } \\
\text { Institucional de bolsa de iniciação à Docência (PIBID) do subprojeto de }\end{array}$ \\
& $\begin{array}{l}\text { Biologia da UFES para a profissionalização docente de seus bolsistas e } \\
\text { formação continuada do Coordenador de Área. Investigações em Ensino de } \\
\text { Ciências, v. 23, n, 2, p. 190-210, 2018. }\end{array}$ \\
\hline
\end{tabular}




\begin{tabular}{|c|c|}
\hline \multirow{3}{*}{ 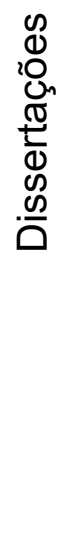 } & $\begin{array}{l}\text { LIRA, F. L. C. O PIBID e a construção da prática docente do curso de } \\
\text { licenciatura em Química da Universidade Federal de Alagoas: concepção, } \\
\text { contribuição e interação. 2016. } 131 \text { f. Dissertação (Mestrado em Educação) - } \\
\text { Universidade Tiradentes, UNIT, 2016. }\end{array}$ \\
\hline & $\begin{array}{l}\text { RECEPUTI, C. C. Percepções de Professores de Licenciaturas em } \\
\text { Química sobre "experimentação", na perspectiva da Teoria das } \\
\text { Representações Sociais. 2019. } 134 \text { f. (Dissertação) Programa de Pós- } \\
\text { Graduação Interunidades em Ensino de Ciências, Universidade de São Paulo, } \\
\text { SP, } 2019 \text {. }\end{array}$ \\
\hline & $\begin{array}{l}\text { SILVA, F. L. Coordenadores de área do PIBID: um olhar sobre o } \\
\text { desenvolvimento profissional. 2015. 154f. (Dissertação). Programa de Pós- } \\
\text { Graduação Interunidades em Ensino de Ciências, Universidade de São Paulo } \\
\text { SP. 2015. }\end{array}$ \\
\hline 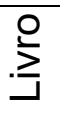 & $\begin{array}{l}\text { GATTI, B.; ANDRÉ, M.; GIMENES, N.; FERRAGUT, L. Um estudo avaliativo } \\
\text { do Programa Institucional de Bolsa de Iniciação à Docência (Pibid). São } \\
\text { Paulo: FCC, } 2014 \text {. }\end{array}$ \\
\hline
\end{tabular}

Fonte: elaborado pelos autores 